\title{
Social influence and external feedback control in humans
}

\author{
Running head: Social influence and feedback control
}

Martin Wei $\aleph^{1}$, Mario Gollwitzer ${ }^{2}$, \& Johannes Hewig ${ }^{3}$

\footnotetext{
${ }^{1}$ Translational Social Neuroscience Unit, Center of Mental Health, Department of Psychiatry, Psychosomatic and Psychotherapy, University of Würzburg, Würzburg, Germany ${ }^{2}$ Department of Psychology, Ludwig-Maximilians-Universität München, München, Germany ${ }^{3}$ Department of Psychology I, Julius-Maximilians-Universität Würzburg, Würzburg, Germany
}

Corresponding author: Martin Weiß (weiss_m11@ukw.de, 0000-0002-0569-0907)

This manuscript is a pre-print (the authors' original version). Please cite responsibly. 
Social influence and feedback control

\begin{abstract}
This article aimed to describe social influence by elucidating the cognitive, affective, and motivational processes present when an individual is confronted with an influence attempt. We hypothesized that these processes are part of a feedback loop system in an individual, which entails a situation (input), a goal state (reference), a comparator, a selection mechanism, a feedback predictor, and an action (output). Each element can become the target of social influence. We aimed to classify/explain different social influences by how these elements are targeted. Trying to persuade another person with strong arguments (i.e., the "central route," according to the Elaboration Likelihood Model) denotes targeting the goal state of the affected individual; coercion targets the selection mechanism; and violence targets action. Summarizing, the present framework aims to categorize, order, and explain phenomena in social influence research using a feedback loop framework focusing on the influenced individual.
\end{abstract}




\section{Social influence and external feedback control in humans}

In everyday life, we often try to influence other people using various tactics. Exemplifying, we may try to persuade colleagues to help us with a difficult task at work by bringing them a surprise gift; we may teach our children to do the right thing by promising them a reward, and try to persuade our academic colleagues that our theories are correct by providing them with arguments that are as strong and convincing as possible. All these social influence tactics have been thoroughly investigated; in fact, social influence is one of the most extensively investigated research domains in social psychology (Harkins et al., 2017). However, an overarching theoretical framework explaining all these tactics (and the processes they trigger) remains, surprisingly, missing.

In this article, we aim to provide such a framework by examining the potential goals of an influencer, individual A, toward an influenced target, individual B. Social influence means acting to produce a specific effect in another person: influencing them to think a particular thought, feel a particular emotion, make a particular decision, and behave in a particular way. Generally, social influence means producing a certain effect on another's system of perception or behavior regulation. Here, we focused more on the effects on the behavioral control system and less on another's perceptual system.

We build on cybernetic models of behavioral regulation, focusing on the elements that these cybernetic models typically entail, providing a theoretical link to cybernetic control models and other feedback regulation models, such as reinforcement learning. The combination of different models may create synergy potentials that can optimize the understanding and prediction of social influence; namely, combining our proposed model and reinforcement learning could help to reveal which specific mechanisms of social influence are particularly rewarding, and therefore important, during social interactions. External social influence can be targeted at any of the elements of cybernetic models and can represent 
Social influence and feedback control

different forms of social influence. Summarizing, we proposed a framework that allows understanding both useful and harmful manipulation tactics in everyday life to extend the general understanding of the broad concept of social influence.

\section{Feedback Loops and Feedback Control}

As a very basic definition of a feedback loop, Carver and Scheier (2000b) described it as a unit of cybernetic control, which is also a system comprising four elements in a particular organization: input, reference, comparator, and output. Input is often described as the "is-state," the reference can also be framed as a goal or "ought-state," the comparator is seen as a core component that detects the distance to the desired outcome ("is-ought discrepancy"), and the output refers to the actual behavior. Carver and Scheier (2000b) differentiated between two types of feedback loops: one describing an attempt to reduce discrepancies between status quo and goal (“approach"), and another describing an attempt to increase discrepancies to a particular "anti-goal" ("avoidance"). Thus, any social influence on another individual will either act through an approach loop or an avoidance feedback loop. These two authors, Carver and Scheier, have linked the cybernetic feedback model to the self-regulation of behavior, attention, and affect (Carver, 2004; Carver \& Scheier, 1981, 2000a). Different approaches have shown that social influence is related to emotional processes (Fischer et al., 2003), (visual) attention (Frick et al., 2018) and self-regulation (vanDellen \& Hoyle, 2010).

Thus, we believe that the cybernetic model is also applicable to social interactions and to understand the self-regulation of behavior, attention, and affect in an actor. Moreover, we see usefulness in examining these processes in a target being influenced by an influencer. Our approach may be one step to relate research on cybernetic action control more intensively, and general action control theories, with the social influence literature. 
Social influence and feedback control

In social interactions, actions usually provoke reactions from others. Therefore, any kind of feedback control may be present in social interactions where the actions of two or more parties influence each other. Classical frameworks by Wiener (1949) and von Bertalanffy (1950) have already investigated the translation of cybernetic regulatory principles into social phenomena. Exemplifying, Wiener (1949) illustrated defective feedback mechanisms in patients who suffered from various types of ataxia; using this dysfunction in voluntary muscle movements, the author created a model for the nervous system and degradation of proprioceptive functions. These translations helped to understand various complex behavioral patterns, such as economic exchange or political negotiation (McClelland \& Fararo, 2006; Robinson, 2007). Accordingly, Jäger et al. (2015) have illustrated how the cybernetic feedback model depicts negotiation situations; specifically, self-regulation, as a feedback loop of goal orientation, identified central challenges in negotiation processes. Specific self-regulation strategies were developed to master the challenges of negotiations based on the individual components of the cybernetic feedback model.

Wolpert et al. (2003) claimed that similar control systems were involved in controlling the behavior of social interaction partners. According to these authors, motor movements (e.g., wave one's hand) can be equated with communicative signals to other people. Namely, motor behavior that affects our physical world is subject to the same principles as social behavior, including communication that influences our social world. In each interaction, the actor generates motor commands based on predictions regarding the target's potential reaction to the commands (e.g., raising one's hand to ask for the waiter). The perceived behavior of the target is then compared with the predicted reaction, closing the loop of social interaction.

Additionally, an individual might respond with many different patterns to the same input. Exemplifying, raising a hand in a lecture might indicate a question or stretching owing 
Social influence and feedback control

to tiredness; depending on how the professor interprets the signal, the professor will either ask or ignore the student. Therefore, the interpretation of social signals may be uncertain and there is often a time lag between the action and the intended reaction. Hence, on a feedback loop system, the demands are different from those on an interaction with non-human physical objects, which are unlikely to deviate from predictable behavior to the same extent or similarly.

Depending on the influencers' aim, they can adapt their social behavior to reduce the discrepancy between the current state and the desired state. The latter applications of feedback control theories have focused on using these theories to explain influencers' behavior; now, we aim to extend this by using feedback control theories to explain the target's (i.e., affected person) behavior. Accordingly, we want to examine the effects of the change in the feedback loop processes from the perspective of the target. Specifically, to explore how and why certain aspects in the feedback loop of the target, which might not be overt, can be influenced in a particularly valuable way to approximate a desired outcome.

\section{Social Influence}

Social influence research has a long tradition, with the concept often having been debated in close relation to the concept of power. An initial, broad, and mathematical equation of power was provided by Lewin (1941), who defined power as the maximum possible force a person A can induce on another person B divided by the maximum resistance of B. Later, French and Raven (1959) defined "influence" as a force that the agent exerts on the target to alter the latter specifically in its behavior, opinions, attitudes, goals, needs, and values. In their first framework, they mainly tried to differentiate several types of exerting power, which will not be detailed herein.

Decades later, with a review by Keltner et al. (2003), research on social power celebrated its rebirth. The concept of social power has often been defined as the ability to 
Social influence and feedback control

control or influence another's thoughts, behavior, and/or feelings in a meaningful way (Fiske, 1993; Thibaut \& Kelley, 1959; Vescio et al., 2003). Nonetheless, the terminologies of "power" and "influence" are sometimes used interchangeably, as outlined by the following examples. French and Raven (1959) partly solved this problem by introducing their definition of influence as a "kinetic power, just as power is potential influence" (p. 152). Accordingly, when speaking about power, a distinction between the potential exertion of power and the concrete exertion of power (i.e., through actions or behavior) became inevitable. Further, we can infer that the exerted power and/or potential power may be attributed differently by the person who exerts social influence, that whom is being socially influenced, and a third-party observer of such an influence. Since we aimed to focus on influence in this study, we chose to use the definition of influence when generally talking about "attempts to affect or change other people" according to Levi and Askay (2015, p. 128).

Importantly, not all social influences are power. Extending the previously proposed model, Raven (1992) went on to focus more on interpersonal influence than on the subtypes of power; specifically, agents now played the role of rational decision makers who calculate the benefits and costs of their abilities to influence a target. This conceptualization approaches the idea that the targets' internal processes may adapt to the agents' attempts to exert influence over them. Combining classical frameworks of feedback literature and insights from social influence research leads to a question: how and where person A can specifically enter the internal feedback loop system of person B and come closer to A's desired outcome?

\section{Combining Feedback Loops and Social Influence}

From a feedback loop perspective, the extension of the potential locus of influence may allow for a new analysis of human social interaction. Hence, we aimed to differentiate various kinds of social influence using the feedback loop perspective of influenced person B, 
Social influence and feedback control

the target. There are several distinct options for where and how the external social influence of an agent can target the elements of a feedback loop system of a target to achieve a desired outcome.

Feedback loops comprise a sequence of stages (i.e., elements), which can be referred to as goal state, situation, feedback prediction, action selection, and action. In the process of adapting the cybernetic feedback model to social influence, we have also slightly modified these terms, coined by Carver and Scheier (2000b), extending them for our purposes. We call the reference value a goal state because it represents the desired outcome of a sequence of actions. In our case, the input is described as the present social situation. During social influence situations, individuals learn through feedback coming from the situation and can predict their own success, a process we called feedback prediction; it influences the socalled comparator/reference, just as do the goal state and the situation. In between, we have interposed the action selection and execution of an action to achieve a goal, that is, the concrete operationalization of the output function; thus, we modified the classical feedback model for social influence. Importantly, some of the suggested examples of influence will aim at an approach feedback loop in the target, while others will address an avoidance loop (Carver \& Scheier, 2000b). These two types of loops are conceptually linked to a promotion and prevention focused on the target (Higgins, 1998, 1999).

As illustrated in Figure 1, to access the internal feedback loop of another person and influence that for one's own benefit, we propose a model comprising five key elements. To ensure greater clarity, we chose to illustrate our model with the following example of two roommates who are about to move out of their shared flat.

Imagine an individual, which we will call the influencer, and another, the target. Both influencer and target are competing through argumentation about the division of a shared 
Social influence and feedback control

television, the goal. If we consider a situation where the influencer wants to buy a brand-new television, the influencer may try to increase the value of the shared object and negotiate a deal to "sell" the television to the target, manipulating the target's goal state (a). In this situation, the influencer persuades the target to understand that the goal is an extraordinary worthwhile investment with many advantages over other goal-like items. Alternatively, the influencer may want to keep the television and try to devalue it to get the target to buy a new one; in this situation, the influencer might persuade the target that the goal is not interesting at all. Both strategies are the direct manipulation of the target's internal goal state or reference; in these examples, the influencer tries to amplify or attenuate the goal for the target by either increasing or decreasing the value attributed to the goal. Hence, the amplification, attenuation, implementation, and elimination of a goal may be relevant principal target strategies.

Although this example was directed to influencing potential goal states, there is another strategy that focuses on a change in the target's situation. Imagine a situation where the target aims to eliminate the mismatch between a situation (e.g., not having a TV) and the goal state (e.g., having the TV). To manipulate the situation (b), or alternatively the target's perception or impression of the situation, the influencer might aim to persuade the target to withdraw from the negotiation or encourage the target toward it. Regarding such withdrawal, the influencer might change the situation by giving the target a cheap TV as a present to eliminate the discrepancy between a goal state (having a TV) and the situation (not having it). This option of influence might prevent a mismatch in the comparator, so the target may take no action. Regarding the aforementioned encouragement, it aims to increase the is-ought discrepancy of the target to trigger an action in the target. In this scenario, the influencer might remove the TV to the influencer's room to deprive the target's access to it, making the is-ought discrepancy highly salient and motivating the target to ask for the TV. Hence, when 
Social influence and feedback control

manipulating the situation, the comparator - as an indicator of the discrepancy between goal state, situation (current state), and feedback prediction - is often consequently affected, thereby often guiding action selection.

When a mismatch exists, for instance, when the goal is interesting to the target, action selection (c) enters in the equation. The influencer might try to convince the target regarding action selection by giving advice toward selecting a distinct action, which might be purposeful - depending on the influencer's interests. Exemplifying, the influencer might give the target good functional advice if the first wants to support goal pursuit; in this hypothesis, an influencer points out to a target how great the quality of the current television is and how time-consuming the search for a new television set could be, or even the complicatedness of the transportation of a novel TV. Alternatively, the influencer may intend to inhibit approach to a specific goal, thus provide advice for action selection; in this hypothesis, the influencer gives advice for the target to buy a new TV. In principle, depending on the influencer's interests, the influencer might suggest actions aimed at either increasing or decreasing the probability that the target reaches the target's goals. The influencer may, hence, try to compromise the probability of success of the target by suggesting unpromising action alternatives.

Fourth, an influence on the target's feedback prediction (d) mechanism might motivate or discourage the target by enhancing or lessening the latter's expectations to achieve the goal (e.g., the influencer can say, "I will negotiate extremely hard with you for this TV, you won't get it easily!" Or oppositely, "why should you deal with all the hazzle of buying a new TV, when you can get this one so easily?"). Hence, the real action might be encouraged or hindered; alternatively, cloying the target's expectations might lead to frustration and disappointment if its actions provisionally fail, leading the target to discontinue potential further efforts. 
Fifth, in the phase of action (e), the influencer might directly change and influence the target's behavior by facilitating or complicating the execution of actions. Exemplifying, the influencer may recognize that the target is about to pack the television, so the first might try to take the television out of the flat earlier. Moreover, in this part of the process, maneuvers such as violence, deception, or intrigue may appear. Examples are the physical capturing of someone who wants to run away, not paying a previously negotiated price because no contract was or will be signed, or accidently breaking the TV, respectively.

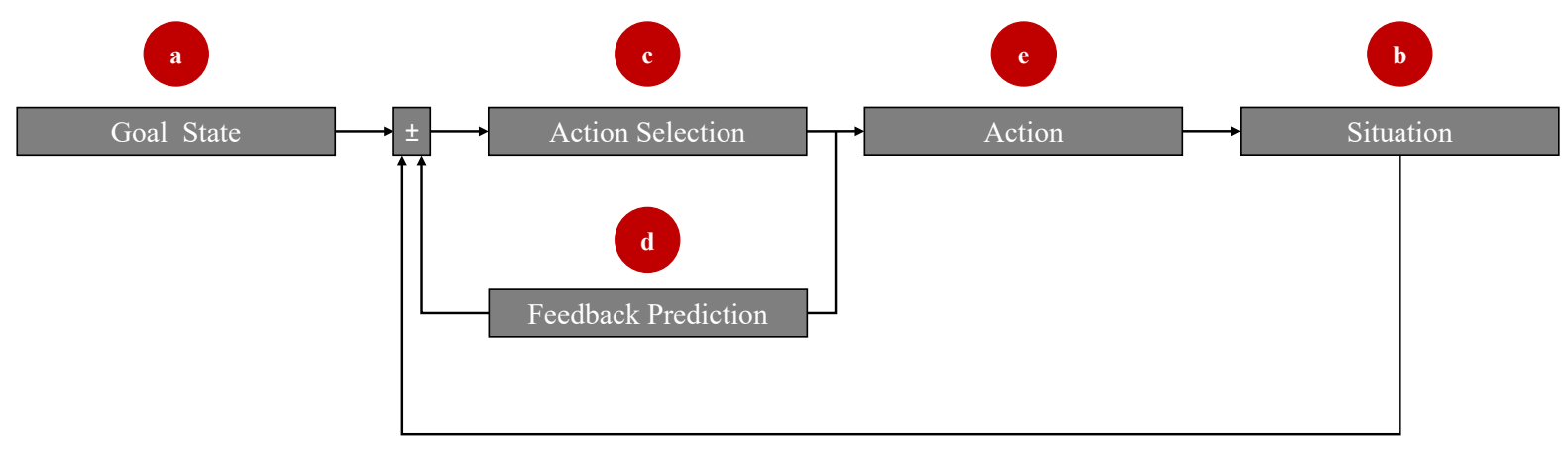

Figure 1. Five entrance gates (a-e) to manipulate the feedback loop in social interactions.

To illustrate our theoretical views, we address the proposed five entrance gates to an individual's internal feedback loop more precisely and mention specific examples in the following subsections. The goal was to differentiate and classify social influence strategies into these five classes using a feedback framework. Then, to illustrate our perspective on social influence, we provide potential situations of negotiation, social norms and sanctions, compliance, advertisement, and nudging.

\section{Social Influence Towards the Goal State}

First, to clarify our understanding of how influence works, we will outline the conceptual differences between persuasion and manipulation; then, we explore how changes in the target can be achieved through persuasion and how this relates to the goal state. 
Social influence and feedback control

Influencing the initial goal state through persuasion might be crucial, as the outcome (i.e., the behavior) can be manipulated even before any action is selected by the target. There is evidence of very different social influence tactics being used in relation to this topic in leadership contexts (Yukl, 1989) and in close relationships (Buss, 1992); however, we will not be able to fully address all here. Instead, we will begin to explore the concept of persuasion through an example. Persuasion is the most appropriate term for what we consider as "influence on the goal state."

A well-known model that explains the consequences of a persuasive message is the elaboration likelihood model of persuasion (ELM; Petty \& Cacioppo, 1986); it provides a dualistic process model that describes attitude changes. The central route comprises a deliberate argumentation that requires a high level of message elaboration to elicit a change in one's attitudes and beliefs. Meanwhile, the peripheral route works with stimuli such as the influencer's attractiveness or level of knowledge, which could lead to increased credibility. Falk and Scholz (2018) defined persuasion as changes in the preferences or behaviors of recipients of information that conform to the active attempts of a communicator to promote such changes.

Aaker and Lee (2001) suggested that the self-regulatory focus of an interaction partner is crucial to what kind of persuasion works properly; this was based on the argument that individuals with an independent self-view (i.e., a self-regulatory focus on promotion) prefer a persuasion that focuses on motivating approach, while those with an interdependent self-view (i.e., a self-regulatory focus on prevention) prefer persuasion that focuses on motivating avoidance. Accordingly, when the persuasion/benefit (either approach or avoidance) of the interaction partner matches the self-regulatory focus (promotion or prevention) of the target, the persuasiveness is more effective. Aaker and Lee (2001) showed these propositions through experiments, and they called this mechanism a "central processing 
Social influence and feedback control

route to persuasion." Interestingly, the prevention and promotion focus are akin to approach and avoidance goals, and are similar to the approach and avoidance loops described in the cybernetic model proposed by Carver (2004). Accordingly, although Aaker and Lee (2001) did not apply a cybernetic view to their study, this perspective might be quite close to that present in, and could be interesting for, persuasion research. Specifically, the persuasive approach suggested by Aaker and Lee (2001) describes an influence on the goal state or reference value, which comprise the central mechanism in a cybernetic feedback loop system; hence, the persuasive approach concurs with the mechanism proposed by the cybernetic feedback loop system.

Empirical evidence indicates that within a prevention-focused situation (rather than a promotion-focused situation), negatively-framed information (compared to positive information) is more likely to lead to effective persuasion, and vice-versa (Holler et al., 2008; Spiegel et al., 2004). Exemplifying, Holler et al. (2008) illustrated a negative framing of the insufficient provision of taxes, with the consequence that the "health care system could not be maintained, and in case of illness outdated methods would be used" (p. 7). For the condition with participants who had a focus on prevention, information emphasizing potential danger led to increased tax compliance - and vice-versa. Summarizing, our framework concurs with the idea that persuasion will likely be most effective if the influence matches the goal category, hence approach/promotion or avoidance/prevention domains.

In our proposed model, the power of persuasion might start to be directly applied when the goal is roughly defined and the influenced person starts to think about the steps needed to reach the goal - that is, during the process of transforming goals into action plans. The manipulation of goals may be operationalized as the implementation of a new goal or the amplification, attenuation, or elimination of an existing goal. To illustrate these differences, we give the following examples. 
Asch (1940) argued that the primary process in influence is not to change the attitude toward, but the meaning of the object. We interpret this change in meaning as describing a change in implicit valuation and an adjustment of the internal cognitive goal structures, which may lead to changes in the choice of explicit goals. Consequently, the change in meaning may lead to attitude changes and, thus, to behavioral changes. Thus, persuading individuals to frame desired goals (regarding a promotion goal) might be a useful strategy for manipulating the feedback loop prior to action selection. Since framing emphasizes the subjective relevance of a person's existing knowledge structures, an essential prerequisite for framing when used as a persuasion mechanism - is the individual being familiar with the topic and having relevant knowledge about the object (Nelson et al., 1997). Accordingly, framing may operationalize the attenuation and amplification of existing goals (e.g., increase the target's motivation to keep the television), goal structures, and their evaluation in an intended direction using existing knowledge structures (e.g., focusing on a potential emotional value of the TV, such as the potential for promoting social gatherings like watching sports events with friends or romantic movies with a partner) and potentially related long-term goals (e.g., focusing on the potential of saving money if the target keeps the TV compared with the buying of a new one).

Furthermore, Haddock et al. (2008) found that persuasion has a greater impact on goals when its cognitive or affective content are matched with the basis of the initial attitude of the individual that should be persuaded - compared with when these are mismatched. Hence, cognitive-oriented individuals (i.e., a higher need for cognition) are more prone to be persuaded by cognitive appeals (Petty et al., 2009), whereas affect-oriented individuals are more likely to be persuaded by an affective appeal; an example would be providing affectoriented individuals with pictures of starving children to motivate them into donating to charity. The rationale is that messages that match, rather than mismatch, individuals' 
Social influence and feedback control

psychological state are processed as more relevant (DeBono \& Packer, 1991). This leads individuals to show greater involvement and enhance their processing, thus increasing the persuasion of strong arguments (Petty \& Cacioppo, 1979). Furthermore, Cesario and Higgins (2008) and Lee and Aaker (2004) found that, for promotion-focused individuals, messages formulated within a gain-frame were more persuasive than those within a loss-frame - and vice-versa for prevention-focused individuals. These authors also showed that, if the message frame was consistent with the participants' regulatory focus, fluency and influence would increase. Here, we remind the reader that prevention and promotion focus are related to approach and avoidance goals. Accordingly, the effects of a match between the gain and loss frames and the respective regulatory focus may be explained, in the cybernetic model, by referring to an approach and avoidance loop (Carver, 2004).

Evidence from consumer research has shown that goal-framing significantly affects persuasion (Min et al., 2013; Poels \& Dewitte, 2008). Exemplifying, Vansteenkiste et al. (2004) showed that framing information about a goal as pursuing an intrinsic objective, versus an extrinsic objective, leads to more desirable goal outcomes (e.g., increased behavioral persistence associated with autonomous motivation) and subsequently higher engagement in a certain activity (Vansteenkiste et al., 2004). Hence, paradigmatically framing intrinsic motivation, promotion focus, or matching initial attitudes can provide a broad contact surface for effective persuasion. In the aforementioned examples, this would apply as person A trying to convince person B that television, or watching TV, does not match B's attitudes, therefore potentially being a waste of time and a distraction to B from B's real internal life goals.

As reported by Chang and Chou (2008) in a study on comparative valence and persuasion, successful persuasion depends on the fit of self-regulatory orientations (prevention and promotion) and comparative valence; specifically, persuasion seemed to be 
most effective when promotion-focused consumers were influenced by a positive comparative valence, and the opposite valence for those prevention-focused. Accordingly, the influencer might be particularly successful in convincing the target that the goal is completely unattractive if the target is a prevention-focused individual. Exemplifying, let us imagine such a target having a debate on the shared television in our original example; the persuasion may work better if the influencer tries to devalue the television by selectively reporting technical data that highlights its outdatedness or its expired warranty. Contrastingly, if the influencer wants to persuade a target toward thinking that the goal is a worthwhile investment, this would work better if the target is promotion-focused. Hence, the influencer could try to increase the target's approach tendencies by emphasizing the practical, monetary, or emotional value of the shared television. The latter would be an attempt to amplify a potential goal by fueling its value, whereas the former would be an attempt to attenuate or even eliminate a goal state within the target by lessening its value.

The implementation of an additional goal may also be relevant in negotiations. Negotiations are often necessary when resources are limited (Aquino, 1998), when there is no opportunity to increase joint profit (i.e., a win-lose or lose-lose situation), or when there is an opportunity to increase the joint profit (i.e., a win-win situation). Imagine individuals A and $\mathrm{B}$ and that both have something which the other wants; meanwhile, both are unsure about the maximum or minimum price of the object that they possess. At this point, one of the two negotiating partners could bring a new target stimulus - irrelevant for oneself - into the negotiation, in an attempt to shift the value for the other party and to influence the negotiation toward one's favor.

Furthermore, a manipulator might influence goals to trigger conformity. For instance, Sherif (1936) conducted an experiment using the autokinetic effect, asking people to estimate how far a dot of light moved; people were asked this question while they were alone and 
while they were in a group. Results showed that the individual assessments were different in these two diverging conditions. Consequently, the goal state may offer space for one's internal regulation to be externally influenced - in the cited experiment, to either adhere to or ignore descriptive norms. Based on this, we argue that by adding an explicit social context, we may implement or amplify a social goal (e.g., maintain or develop social relationships; gain recognition from others) in the manipulated person; conversely, this social goal may not be present, or at least not as strong, when the person is alone.

In social psychology, this is reflected in the basic motives of social influence. Deutsch and Gerard (1955) suggested that conformity is based on the principles of normative and informational influence. While normative influence aims at harmony and conformity with the expectations of others, informational influence aims to reduce uncertainty by incorporating others' information into one's worldview. Thus, to manipulate or stimulate certain goals in the target from the Sherif's example above, the influencer may potentially address these two types of conformity or even try to influence the internal goal of correctly assessing the dots. Conformity can, thus, be a potential external regulator that facilitates or inhibits certain persuasive processes, and not only at the goal stage. Namely, whenever an influencer can activate social norms to try and influence people toward achieving conformity, other levels of the feedback loop may be affected. Conformity may, for example, also restrict or postpone the selection of actions, making actions that conform to social norms more likely to occur.

\section{Social Influence on the Subjective Situation}

A core prerequisite for having an impact on a specific current situation is awareness, both about the situation and the potential to manipulate it. In our shared television example, this is reflected by the influencer's subjective impression of being capable to win the negotiation. If the influencer was the target's property owner, however, the first could easily change the situation by declaring that the television is an apartment inventory, potentially 
Social influence and feedback control

changing the legality of the negotiation. The influencer's action in this situation can lead the target to think about its own reduced financial capabilities, or also demonstrate the influencer's own enhanced capabilities to increase the chances for the target to withdrawal from the negotiation; these could reduce the risk, for example, of a physical conflict (von Hippel \& Trivers, 2011).

Another example of how the situation can be specifically manipulated was provided by Cialdini et al. (1990). The authors varied (based on descriptive norms) waste throwing behavior by manipulating the amount of waste in different situations; their results showed that it is more likely for people to drop waste in a polluted environment than in a cleaner environment. However, a confederate could enhance the norm by dropping waste in both polluted and clean environments. In the already polluted environment, attention was drawn to the environment and the participants were more likely to drop waste; in the clean environment, the waste was more salient and the participants were less likely to drop waste. This shows that the discrepancy between the situation and internal goal states can be manipulated; specifically, in the absence of waste, the dropping of waste by someone is more likely to create a discrepancy in the comparator, changing individuals' behavior.

Applied to our roommate example, to influence the situation, the influencer could change the location where a possibly conflicting negotiation would occur. Specifically, the influencer might choose a location or situation that confers the influencer an advantageous position. Exemplifying, the influencer may be good at gambling or at a sport at which the target is not good, so the influencer might choose a bar or sports event for the discussion to occur, making the goal part of a stake and compromising the target, who would possibly feel uncomfortable in the desired scenario. Such an influence changes the current situation and potentially the subjective situation of the target, having subsequent consequences in the feedback loop. 
Social influence and feedback control

If we change the situation to a gamble, the discrepancy between the goal state and the situation (i.e., the goal is not yet in the possession of the target) becomes amplified. The reason for this amplification here is not the absolute difference between goal and situation, as the goal remains the same and is still not in the target's possession; instead, the reason is that the target may be less capable of showing behavior that could successfully lead to the goal, denoting that the feedback prediction or success probability is lowered. Consequently, a larger discrepancy is created in the comparator. An alternative theoretical scenario for this influence would be present if the influencer could lead the target from being in the flat to being elsewhere. In this thought experiment, the spatial distance between the goal and the target would be enlarged. Consequently, action opportunities would be decreased and action selection would be influenced - because some behavioral options may become impossible when the goal is afar. Hence, the performance of an action would be much more difficult, decreasing the probability of success and influencing feedback prediction.

Adjacent concepts that alter the perception of a situation, instead of the facts themselves, can be found in social comparisons; examples are upward and downward comparisons. According to Wills (1981), a possible solution to overcome the experience of negative affect is to increase subjective well-being through a downward social comparison (i.e., with a less fortunate individual). The counterpart, upward comparison (Wheeler, 1966), is described to be motivated by the intention to increase one's achievements. In our model, social agents might strategically select to conduct upward comparison to manipulate the calculation in the comparator; for example, providing an upward comparison of the target's goal to make the goal appear unattractive. Hence, the influencer might point to newer and better models of TV if the intention is to keep the shared TV; if the intention is to sell the shared TV, the reference may be to older models of TV or to the valuable functions of the shared TV. 
Social influence and feedback control

Summarizing, the specific reason for influencing a situation is often aimed at subsequently affecting the different mechanisms of the feedback model. According to the mechanism of upward and downward comparison, an influence on the perceived state may provoke a discrepancy in the comparator of the feedback loop, or even obscure an existing one. Furthermore, one may also influence the situation to increase the basic physical distance between the goal and the target (in our example, person A moves the shared TV from the flat to A's parents' house). Another reason for influencing might be to decrease action opportunities and, thus, influence action selection (in our example, A replaces the locks of the shared flat). In both cases, the performance of a successful action by the target becomes increasingly difficult, denoting that the influence decreases the probability of success, thereafter affecting feedback prediction.

\section{Social Influence on Action Selection}

At the stage of action selection, persuasion, in its most common sense, might effectively alter the internal feedback loop of others. Since the concept of persuasion is present in nearly every textbook of social psychology, and there is already a specific book called "The Persuasion Handbook: Developments in Theory and Practice," edited by Dillard and Pfau (2002), we will only present a very small extract of the topic that is relevant to our

study; specifically, we aim to illustrate our interpretation of persuasion based on the feedback framework and to develop a systematic approach according to the affected aspects of the feedback loop.

Nonetheless, we first want to mention that it is quite difficult to isolate persuasion uniquely aimed at action selection - that is, deliberations about the optimal strategy for goal attainment - compared with persuasion aiming at goal structures, that is, basic preferences of an individual (see above section "Social Influence towards the Goal State"). However, from 
Social influence and feedback control

the feedback loop perspective, we think that the separation might be useful for understanding the differences in the mechanism of persuasion for these two different kinds of targets.

A relevant aspect of persuasion is that the argument outlined in the influencer's statement matches the function underlying the target's dominating attitudes (Lavine \& Snyder, 1996). This means that people have certain attitude functions for different issues, and not all are equally accessible to persuasive attempts. Therefore, the better the influencer knows the target's attitude functions, the easier it is to evaluate whether the persuasion of the target's action selection will be promising or not. Since weak arguments were found to be unable to enhance persuasion, it may be relevant for the influencer to present a statement with a cogent argument (Petty \& Wegener, 1998). Further, persuasive messages that address a particularly important attitude function are processed more carefully, being consequently less influential (Marsh et al., 1997). Summarizing, there are various factors that may lead to the success or failure of a persuasion aimed at the action selection of a target, which intends to influence another person's internal feedback loop.

Chambon and Haggard (2012) proposed a model of a prospect aspect of sense of agency, meaning that early signals that reflect action selection processing contribute directly to an experiential sense of control. A positive judgment of agency about action effects enables us to adjust to a dynamic environment and direct behavior toward a goal (Elsner \& Hommel, 2001; Hommel \& Elsner, 2009). Thus, it is useful to reinforce prioritized actions that lead to control over the environment (Redgrave et al., 2008; Redgrave \& Gurney, 2006). At this stage, which is highly difficult to influence directly, an external source might be able to manipulate the internal feedback loop. We presume that, at this distinct stage of the feedback loop, arguments which were previously expressed by others before action selection may come to mind. 
Social influence and feedback control

A well-known influence strategy of action selection used in many psychological experiments is the concept of priming. According to Eitam and Higgins (2010) and Higgins and Eitam (2014), priming effects include stimulation of an individual's representation of certain social target stimuli. On the one hand, such stimulation influences evaluations of social targets; on the other, it influences the action or action selection. Further, by means of priming, it is possible to accomplish influence both by producing awareness in the target about the potential manipulation or by a covert use of the previously implemented activations to alter judgment or action (Loersch \& Payne, 2011).

Returning to our roommate, shared TV example, let us imagine the influencer informing the target that the first wants to donate the TV to a charity organization. If both parties actually aim to keep the TV, the target might be displeased that the influencer aims to donate the goal - and potentially fear the possible loss of the goal. Since the influencer knows how the target reacts to such an unwanted approach, the influencer can use this knowledge to post an advertisement about the topic in a social media channel, especially so if the influencer knows that the target will see this advertisement. This provocation can lead to two possible scenarios. First, the target could withdraw from wanting the television owing to feelings of uncomfortableness related to the influencer's ignorance about how donating the goal would make the target feel. Alternatively, this provocation could reinforce the target's attempts to acquire the goal to prohibit the unwanted actions of the influencer. The influencer could successfully benefit from this simple influence strategy based on the re-evaluation processes of the target.

Another possible option to influence action selection is to try to achieve obedience. The most well-known experiments on obedience have been conducted by Milgram (1963); the author showed, through an experiment, how strongly subjects can comply with commands despite such obedience creating an allegedly life-threatening situation for the other party. In 
Social influence and feedback control

the experiment, a fictional setting of an authority-subordinate relationship was enough to create a goal state (i.e., teach the other "subject") which had to be achieved by a predetermined action selection (i.e., punishment via electric shocks). The experimenter, as the authority, was sufficient to uphold the preselected action selection of providing electric shocks. Later research replicated these findings, for example, in a virtual environment (Slater et al., 2006). Although this was a fictional setting, most participants acted according to their given instructions, supporting the importance of predetermined action selection as a potential influence strategy. Apart from action selection, the described setting could also influence the goal state, since the notion of educating someone by applying electric shocks might influence people differently depending on their idea of morality in education.

Furthermore, Stayton et al. (1971) investigated the origins of socialization according to infant obedience, reporting that the most frequent occurrences of obedience are simple compliance behaviors to external signals, not internalized control instances . Hence, there seems to be some form of educational preparedness that makes humans receptive to social influence, specifically obedience, through verbal instructions. A conceptually related example might be the foot-in-the-door technique (Freedman \& Fraser, 1966), which brings us to the phenomenon of compliance, because no figure of authority is necessarily involved in this example - whereas obedience denotes the existence of such a figure. In this technique, the target person is first asked to comply with a small request, which is usually minimally invasive, a request such that the target person will almost certainly give an affirmative answer to. After assuring the fulfillment of this request, a larger, often related request is, once more, made. The strategy is considered successful if the compliance rate is higher for those who received the original request than for those who did not. 
Social influence and feedback control

If the influencer is perceived as highly reputable and trusted by the target, the target may potentially be obedient to or compliant with the influencer's advice, although the target would intuitively like to approach the goal as often as possible.

In our shared TV example, the influencer might influence the target regarding action selection by suggesting the selection of a distinct action, which might be somewhat purposeful. However, this only works well if the influencer is perceived as highly reputable and trusted by the target, which could make the target potentially obedient or compliant. In principle, depending on the influencer's interests, the influencer might suggest actions that aim at either increasing or decreasing the probability of the target to reach the latter's goals. When intending to compromise the probability of success, the influencer may try to suggest unpromising action alternatives; if the influencer appears to have more experience or technical knowledge, the influencer might easily play the role of an authority that the target should obey, which thereby allows for the influencer to evaluate whether it is worth investing in the TV.

Further social manipulation tactics might fall into this category, but will remain unaddressed in this study, such as coercion, hardball, or silent treatment (see Buss, 1992). All such tactics use strong aversive motivational tools that are supposed to enforce a certain action selection in the target. Finally, another strategy, nudging (see example further below), is also a potential approach to influence action selection.

\section{Social Influence on the Behavior While Acting}

The influence on the actual behavior is possibly the most complicated part to isolate in the proposed feedback model. In this study, we tried to grasp attentional, perceptive, or cognitive manipulations in the preceding stages of entering a feedback loop; hence, when talking about behavior in this subsection, we refer to physically-induced manipulation. We also tried to debate, in this subsection, the influences that are closely linked to the behavioral 
level. To produce a direct behavioral change during its occurrence, we presume that the possibilities are restricted to violence or deceptive redirections of an action (e.g., pretending to be courier for someone and then delivering completely different information). Further, all kinds of sports activities that comprise competitive interaction components may contain forms of direct social influence on others' action or behavior. In tennis, for example, a direct form of behavioral influence would be a player aiming to hit the ball in such a way that makes it impossible for the other player to hit the ball back.

Much of the social influence research focuses, instead, on social norms and more subtle psychological influence processes. In these investigations, the exposure of an individual to behaviors of close friends or close others (i.e., a descriptive norm) was found to be sufficient to alter that individual's behavior (Cullum et al., 2010; Goldstein et al., 2008). Consequently, the social influence induced by social norms might alter the internal feedback loop regarding action selection; specifically, the selected action may be pre-activated and made more salient by priming, which occurs through exposure to close friends' behavior. Additionally, participants might deduce intentions from their friends' behavior and subsequently build goals on these deductions.

Meanwhile, actively promoting and/or physically enforcing social norms might alter the future behavior of others. There are even settings in which people are motivated to ostracize norm-deviant behavior to strengthen their own position in a group (Willer et al., 2009). This will not only directly affect the punished person but also indirectly influence many others through the mechanisms mentioned in previous subsections; for example, implementing an avoidance goal (punishment), influencing action selection (favoring active avoidance choices regarding punishment), and altering feedback prediction (reducing the expected success of behavior opposing the influencer). 


\section{Social Influence on Feedback Prediction}

In reinforcement learning theories, feedback prediction is defined as the predicted reward value of performing an action. These values are utilized by our brains to adapt behavior by biasing action selection towards instrumental actions with the highest predicted reward value (Redgrave et al., 1999). In a broader sense of value based on expectancy models, feedback prediction serves to optimize goal pursuit and entails the combination of reward value and the probability of success. Regarding behavioral actions, those that are instrumental to achieving goals with higher predicted outcome values are chosen more often (Samejima et al., 2005) and more rapidly (Brown \& Bowman, 1995) than those with lower values. Furthermore, the reward system is also known to prefer actions and goals that implicate actual (Bednark \& Franz, 2014; Behne et al., 2008) versus potential (Leotti \& Delgado, 2011; Tricomi et al., 2004) control over the environment.

In our proposed model, giving an individual a feeling of control, or the lack thereof, might be a successful strategy to alter an internal feedback loop. Increasing the subjective probability of success of a certain course of action for a target may stimulate or motivate this action, whereas reducing this probability may discourage that action course. As aforementioned (see "Social Influence on the Subjective Situation"), a manipulation of the situation may often be a valid pathway when trying to influence feedback prediction.

In some cases, when trying to influence feedback prediction, the influencer may need to deceive the target by classifying the target's goal proximity. Persuasion in the form of deception has the goal of instilling a false belief in the mind of the interlocutor to manipulate how the interaction unfolds (Sip et al., 2012). Hence, when talking about deception, we refer to attempts at modulating the perspective/belief of a target to reach the influencer's goal. Since we want to structure a framework about how to enter a feedback loop, we will not investigate in-depth the possible consequences of telling a falsehood or the affective aspects that may arise 
when a deception may be detected. Further, the term deception may have a slightly criminal and immoral connotation, meanings which do not concur with its function in the framework we propose. Here, we use this term as a functional strategy to approach goals in a social interaction by influencing other people in their feedback prediction process. The central aim of such deceptions would be for the influencer to alter the target's success predictions; specifically, either exaggerating them if the influencer wants the target to be successful or abridging them if the influencer wants the target to be discouraged from success.

Framing is key in achieving this type of influence; it is an influence strategy that emphasizes the distinct attributes of an issue over other potential consequences (Nelson et al., 1997; Nelson \& Kinder, 1996; Price \& Tewksbury, 1997), and its effectiveness seems to depend on familiarity with the issue. The reason might be that persons who are familiar with a certain topic have a deeper knowledge structure compared with individuals who are unfamiliar with it. Imagining our shared TV example, a possible framing regarding devaluation could be the phrase, "everybody can buy such a TV anywhere easily;" whereas a possible valorization of the target could be the phrase, "you won't get such a TV easily for such a price." Many studies have explored this basic kind of strategy (Druckman, 2001; Gächter et al., 2009; Tversky \& Kahneman, 1981).

\section{Examples for Applications of the Model}

In the following subsections, we describe studies dealing with different aspects of social influence and persuasion and point out, according to our model, where different characteristics might alter the internal feedback loop of participants at different stages. Since the promotion and prevention focus are linked to the approach and avoidance goals, respectively, and can be directly linked to the cybernetic feedback model, most of the selected experiments refer to the regulatory focus theory (Higgins, 1997). Regulatory focus theory examines the relationship between a person's motivation and how that person achieves 
a goal, postulating two separate and independent self-regulatory orientations: prevention and promotion focus. In accordance with that model, we posit that either a prevention or promotion feedback loop will occur in a target person. Of course, there may be overlapping aspects between the studies, and it may be that not in every experiment all aspects of our model will be addressed and implemented easily. However, by altering the experiments, we tried to elucidate both simple and creative solutions to describe manipulation options according to our model. Although we believe that the mechanisms of our feedback model could be investigated most effectively through laboratory experiments, we have included both field and laboratory experiments hereinafter.

Before starting with the research examples, we will briefly describe the systematic approach we used to analyze studies in this domain. First, we detected the relevant goals in the experiment (e.g., social goals, personal goals, etc.) and whether the value of a goal was manipulated or an additional goal was included. Exemplifying, introducing a social comparison will add social goals to an otherwise private context. Second, we analyzed the situational characteristics that are influenced. Third, we examined whether action selection was manipulated, particularly whether a specific behavioral choice was promoted. Fourth, we examined action opportunities or direct effects on action execution. Fifth, we examined whether and how social influence affects feedback prediction and goal state versus situation discrepancy. For example, by manipulating a target's subjective goal attainment probability.

In the following subsections, we first explain the findings, then apply our model, and then derive potential additional experimental manipulations based on our framework.

\section{Descriptive and Injunctive Social Norms}

Descriptive norms refer to the behavior of relevant others (e.g., peers, family, society) and provide a socially determined standard for behaviors that are effective (i.e., what individuals typically do). Injunctive norms refer to appeals about what other members of 
Social influence and feedback control

society approve or disapprove of. Thereby, and as argued by Melnyk et al. (2013), these norms motivate engagement in specific behaviors depending on their social rewards, in the case of descriptive norms, and punishment, in the case of injunctive norms.

These authors investigated the effect of regulatory focus on the influence of descriptive and injunctive social norms in the context of sustainable food choices. In the first three experiments, state regulatory focus was induced as a between-variable to participants. For norm induction, participants were shown a fictitious website covering information on fair-trade coffee using a text framed with either descriptive or injunctive norms; participants were requested to answer to several questions regarding attitudes toward fair-trade coffee and their planned buying intentions. While controlling for past buying behavior, an induced promotion focus increased the efficiency of descriptive norms, as attitudes and intentions were in favor of sustainable choices. Contrastingly, injunctive norms were not influenced by the state of the regulatory focus.

While the second experiment aimed at the perceived fluency of the different normative messages and is of secondary interest for us, the third experiment was a replication of the first, using organic milk instead of fair-trade coffee. Here, regulatory focus induction was included in the text message and not conducted separately, as in the first experiment. However, the results were comparable to those of the first experiment. Taken together, promotion focus was shown to increase buying intentions in the descriptive norm condition, whereas no differences were found in the injunctive norm condition. The latter, nonetheless, might owe to a ceiling effect, since intentions were as high as in the promotion-focused descriptive conditions. The former is in line with the influence of descriptive norms on a promotion-feedback loop. 
Social influence and feedback control

As participants were invited to evaluate the design of a website, their goal orientation was distracted from the actual research goal of the scientists. However, social comparisons regarding relevant others (i.e., other students), which were used in the descriptive norm induction ("A great number of [...] students purchase Fair Trade coffee on a regular base"), might have activated an explicit awareness of social norms regarding pro-environmental behavior. Importantly, environmental goals were not different between conditions, so that only the presence of different social goals was relevant.

Particularly, the presence of an injunctive norm generally increased intentions, so it was sufficient to influence behavior. In our model, we argued that this owed to the inclusion and presence of a social goal. In the descriptive norm condition, we argued that the mere presence of a promotion focus was sufficient to activate a goal in participants. Moreover, participants conducted the experiment together with others in one room, facilitating implicit social comparisons with peers. Consequently, the situation was influenced by the data collection (i.e., in groups), denoting that the state-induced regulatory focus might have become fragile, especially for individuals who were sensitive to social pressure in the presence of others.

Action selection was manipulated by the different normative framings present in the website content. However, as participants were instructed to focus on design features, the target manipulation tool of the study was implicit. The distraction from the study goal might have enabled participants to answer to the dependent variable questions for reasons other than the experimental manipulation (e.g., general pro-environmental attitudes). In the presented experiments, nonetheless, there was no direct influence on action selection because they were based on text reading and questionnaires. However, the success of feedback prediction depends on interindividual differences; specifically, individuals with pro-environmental attitudes and a low budget might have perceived the situation as a trigger for a discrepancy 
Social influence and feedback control

between the personal goal state and the is state (i.e., they would like to buy fair-trade coffee, but cannot afford it). Regarding the apparent study goal, that is, evaluating a website design, a discrepancy between goal state and situation might only have been present if the website design was overly perfect, a condition that would have led participants to fail in giving suggestions and thereby miss the goal.

To investigate in-depth the interaction among regulatory focus and descriptive norms, and the first and injunctive norms, future research based on the cited study might add several conditions and prerequisites. We propose two additional conditions with an explicit goal of focusing on the text by asking participants whether the content could lead to more purchases of fair-trade products (versus a control group). Therefore, using our framework, not only differences in the goal state but also finer differences in the influence on action selection could be examined. Further, we suggest future studies to place a stronger focus on goalframing, rather than on peers' behavior; for instance, the buying of fair-trade coffee could be presented for students as a form to support the promotion of local and sustainable food production or prevent the exploitation of the local environment and farmers.

Goldstein et al. (2008) investigated, through two field experiments, the influence of three different towel reuse signs in hotel rooms on pro-environmental behavior. The hotel guests were not informed about their participation in the experiment and were randomly assigned to one of three towel-reuse conditions.

In the first experiment, the first condition corresponded to an industry standard that emphasized towel reuse for environmental reasons, but without referring to any descriptive and normative information. The second condition corresponded to a global standard describing the towel reuse behavior of all hotel guests. The third condition was a provincial norm that described the towel reuse behavior of other guests who had booked the exact same 
room. The results showed that the current situation (i.e., the specific hotel room, third condition) had a significant impact on behavior; the provincial norm led to more towel reuse than the global and the industry standards. In the second experiment, the authors replicated the findings of the first experiment, showing that hotel guests conformed more to the provincial norm compared with the norms of other hotel guests (e.g., gender identity). ${ }^{1}$ Unfortunately, a control condition without signs was missing.

The central difference between the three main conditions was the presence of a social comparison in the second and third conditions. This may introduce additional social goal and social motivation for the target; with such additions, participants were prompted to compare their behavior with, and identify it as similar or dissimilar to, the proposed social comparison group. This may have motivated behavior through goals such as social attachment. As the hotel guests were ostensibly not aware of their study participation, the manipulation of the goal state and the study aim was probably not recognized by participants. This is an advantage over laboratory experiments, although the latter might induce an artificial focus on social norms. However, environmental characteristics, such as the type of hotel (in this case a "midpriced hotel of a chain"), might subconsciously have implemented a general behavioral goal; for instance, an eco-hotel might increase pro-environmental behavior. A replication of these experiments using a controlled setting would allow for investigating general proenvironmental behavior without any norms (e.g., avoid extensive energy wasting behavior), which might more accurately represent an internal goal state compared with the influence of signs, like those in the experiment.

\footnotetext{
${ }^{1}$ Schultz et al. (2008) could not replicate differences between the two types of normative messages. Hence, further research is needed to unravel conditions under which different types of messages increase proenvironmental behavior in this context.
} 
An alternative experimental manipulation of the situation could be to use absolute numbers of towels reused per day compared with relative numbers, because the situation in this case depends on the booked nights; using this approach, researchers may assess behavioral changes for guests with different bookings, and the behavior might be initially different for those staying only one night versus staying one week. Another scenario would be that the signs addressing different standards could be replaced with specific reuse goals. For example, if the goal is 10 reused towels per week, participants' behavior might differ if eight have already been reused when they enter the room compared with a situation where only two have been reused.

The selected study clearly focused on manipulating action selection using different signs. However, the best manipulation strategy they used to change action selection was to address the current situation of participants (i.e., towel reuse behavior of other guests who had booked the same room). This is a particularly good example to show that, during the physical absence of social agents, action selection needs to and can be manipulated via a preceding operation (i.e., manipulating the goal state or the situation). In this scenario, one possibility to manipulate action directly, in an ethical manner, would have been to implement a condition where cleaning staff would generally put the towels back; this would thereby try to force participants to reuse them. Then, participants could also have to invest more energy into not reusing the towels; for example, it could be requested for hotel guests to have to place a sign that demonstrates their urge for staff to clean the towels with the sign.

To address the action directly and feedback prediction simultaneously, an additional reward or token system for towel reuse behavior could be applied. In a feedback model, a large discrepancy between the internal reference value (i.e., own preference for reusing towels) and external information (e.g., a daily feedback sign placed in the bathroom that courteously evaluates the guest's behavior) would lead to a larger difference in the 
Social influence and feedback control

comparator and, consequently, to larger adjustments in action selection and action execution to reduce this discrepancy (i.e., more towel reuse if the initial preference to reuse towels was low). Summarizing, by extending and altering the study setup with these examples, future studies could unravel, in more detail, which pathway for addressing social norms might be the best to foster pro-environmental behavior within a feedback loop framework.

\section{Compliance}

To illustrate the merit of our model regarding compliance, we apply our framework to research related to promotion and prevention focus in a healthcare context (Spiegel et al., 2004). The researchers asked individuals to participate in a study on the nutritional habits of college students. Therefore, participants received a daily nutrition log booklet to be used for recording their daily consumption of fruits and vegetables; they were instructed to return a week later with a completed booklet. Together with the booklet, participants received a questionnaire regarding food habits and health messages. Using a between-subjects design, participants received four different messages covering a framing of the regulatory focus (addressing the imagined benefits of compliance) and a framing of the outcome (addressing the imagined costs of non-compliance). The dependent variable was the effectiveness of health messages in changing behavior, that is, eating more fruits and vegetables after one week. The results showed that when the goal of eating more fruits and vegetables was presented as a health promotion-focused issue, messages that required imagining the potential benefits of successful dietary change were more effective than messages that required imagining the potential costs of dietary change failure. The opposite was true when the goal of eating more fruits and vegetables was presented as a health prevention-focused issue, and no main effects of regulatory focus or outcome framing were found.

Of interest was their Experiment 2, where participants were requested to read either a promotion- or a prevention-framed health message urging them to eat more fruits and 
Social influence and feedback control

vegetables; namely, a goal was explicitly set. In line with regulatory focus theory and our model, we argue that social influence works best when targeting either a promotion (approach) or a prevention (avoidance) feedback loop in the target. By giving participants specific action planning options in addition to the goal state (imagination of benefits), researchers were able to directly address action selection. Accordingly, a fit between an influence on action selection (e.g., identifying a good time) and an influence on the goal (i.e., outcome benefits) may provide the best results to influence action selection. Future research, nonetheless, could aim to manipulate feedback prediction by adding comparative information about the degree and likelihood of success toward dietary change.

\section{Advertisement}

Zhao and Pechmann (2007) examined the impact of regulatory focus and different framing strategies on the persuasiveness of antismoking advertisements for high school students. The authors created four advertisements on antismoking that differed in their regulatory focus (promotion versus prevention) and outcome framing (favorable versus unfavorable). In the first experiment, the authors used a three-factor between-design categorization, classifying participants depending on their dominant regulatory focus (assessed via a validated scale), the advertisement's regulatory focus, and the outcome framing. Moreover, a control group with a non-smoking-related advertisement was included. The criterion was the intention not to smoke cigarettes. The results indicated that the antismoking advertisements worked best when viewers' regulatory focus, the advertisement's regulatory focus, and the message framing functioned synergistically; that is, participants with promotion focus who viewed promotion-focused advertisements with a favorable outcome framing, as well as participants with prevention focus who viewed preventionfocused advertisements with an unfavorable outcome framing. While the general design was 
identical in the second experiment, it added active manipulation on participants' regulatory focus. The authors replicated the findings of the first experiment.

The participants in this study were randomly assigned to the groups and watched an episode of a TV show where the advertisements were presented between several filler advertisements. The focus of this research was the promotion of antismoking. Thus, the goal that was to be implemented or strengthened in targets was non-smoking, which might be pursued by addressing health issues. However, advertisements also specifically added social goals to the context of smoking, in particular social acknowledgement and social attachment. Thus, the goal level was directly addressed with these advertisements, in which the social environment provided positive and negative feedback toward the depicted smoker.

According to our framework, the target of the presented experiments was to manipulate behavior (i.e., the post-experimental questionnaire assessing the intention to smoke) via the presentation of these advertisements. Action selection was influenced directly by the inclusion of the advice, "Don't smoke!" In the advertisement, which alone did not seem to change behavior as compared with that in the control group. Feedback prediction was influenced in the study by showing the participants the potential social consequences of smoking and non-smoking through the behavior present in the social context of the advertisement. Summarizing, the study clearly showed that a match among individual regulatory focus, outcome type, and the regulatory or motivational state leads to the strongest changes in behavior. In the feedback loop framework, we argue that a manipulation works on a specific feedback loop in a target; ideally, all aspects of the manipulation should converge on the same feedback loop, which should be either a promotion/approach loop or a prevention/avoidance loop. 
To extend the experimental design to add manipulation possibilities according to our framework, we propose several options. Although the authors included a control condition for the task, all participants were classified by a regulatory focus measure or induction. An additional, unbiased control group without regulatory focus induction may be included in future research. Additionally, the intention to smoke might be more present in contexts outside a school classroom; thus, future studies could examine the influence of situational factors, such as watching the TV show inside the classroom and on a smartphone in a corner of the schoolyard. Situational influences on intentions might, in turn, be examined by measuring baseline intentions to smoke and previous smoking behavior, because these state variables might interact with the implementation of the social goals using the advertisements. In smokers or people with stronger smoking intentions, social goal implementation probably leads to a stronger is-ought discrepancy, which may either increase adjustments or lead to reactance - for example, if the discrepancy is too large for an individual to deal. Future research could, thus, assess the level of the is-ought discrepancy in behavior.

\section{Nudging}

According to Thaler and Sunstein (2008), nudging refers to interventions implemented by persons with responsibilities over a group to help individuals in the group make responsible decisions. To explore the application of our model in an example, we used a study investigating the effects of nudging on when and why users opt for online ID verification in the context of digital platforms (Schneider et al., 2017). The researchers combined, on a fictional carsharing platform, assurance statements as claims (which were framed as promotion and prevention focus) with supporting data regarding the convenience, security, and privacy aspects of online verification (present versus absent). The dependent variable was the choice for online verification (i.e., a webcam session with a verification agent) compared with offline verification (e.g., physically visiting a post office). In addition 
to the four experimental groups (two claims, each with present or absent data), a control group without claims and data was included. The results showed that, in the absence of data, participants more often chose online verification in the promotion focus group compared with in the prevention focus group. However, this effect was reversed in the presence of data, as participants chose online verification more often in the prevention focus group than in the promotion focus group.

Concerning the goal state to reach verification, two paths of action were available. Regarding action selection, participants faced a binary choice, namely, online versus offline verification. As participants were asked to put themselves in the position of a prospective carsharing user, the goal of completing the registration process was implemented. In this case, the value of the goal was not manipulated, but the means to achieve it was (i.e., online versus offline verification). Depending on the relevance of the carsharing platform for participants, their personal goals might have amplified the goal state. For example, participants who would like to use carsharing platforms more often were motivated to participate. As the study was conducted online and participants were asked to take the perspective of a carsharing user, a general bias towards a digital context might have implicitly influenced the situation. The manipulation of action selection was targeted by increasing the credibility of online verification through the inclusion of security-related data on the platform and the regulatory focus framing of the claims. This study provides a good example of how to target action selection, rather than goal structures.

By conducting the experiment in a laboratory, researchers could manipulate situational factors, such as the conduction of offline verification in a controlled manner and in a separate room — which served to reduce the influence of the distance between participants' home and a post office. The action could also have been manipulated by implementing a queue (versus none) condition in the offline verification process, which would focus also on 
the time-related advantages of the online process. Regarding how to influence feedback prediction, they could have presented regulatory focus framings and support security data using a sequential design, evaluated the choice option more than once, and given participants more information about the likelihood of success and the difficulties in attaining the goal.

To apply our model, we selected a series of studies on dietary decisions (Prinsen et al., 2013). The rationale was that individuals conform to the eating behavior of others and, therefore, should be affected by the corresponding environmental cues. The authors conducted both field and laboratory experiments using a between-group design with a bowl of hand-wrapped chocolates, utilizing the amount of chocolate taken as the outcome variable. The researchers placed a second bowl next to the bowl with hand-wrapped chocolates; this second bowl was filled with twenty wrappers for one group of participants and for the second group of participants, this bowl was empty when they entered the natural setting/laboratory. Participants were more likely to take chocolates in the presence of an environmental cue (i.e., empty wrappers), indicating that previous participants also took chocolate. In another experiment, the authors manipulated the healthiness of the snack (healthy snack compared with unhealthy snack) and the goal prime (a magazine on healthy eating versus a magazine on hedonic eating) to measure snack choice. The results indicated that participants also conformed to environmental cues about the type of food that others chose, not only about the mere eating behavior. In all experiments, participants were given a covert story which stated that there was a waiting time until the experiment started; the authors, nonetheless, assessed the experiments during this supposedly waiting time.

In the first two experiments, there was no food-related goal state implemented or directly manipulated for participants. However, since participants had to answer to several questions (e.g., the time difference to their last meal), we cannot completely rule out that at least some of the participants focused on the food. Primarily, participants in the laboratory 
settings were instructed that the study aimed to assess a reaction time (Experiment 2) or their completion of a cognitive task (Experiment 3). The empty wrappers may have worked in two ways to manipulate the situation; first, they may disinhibit eating behavior because others have before the participants had eaten the chocolate, denoting the activation of social motivation to act similarly to how others have acted. Second, they may have more directly influenced action selection through promoting simple behavioral imitation.

To manipulate the goal state, a possible experimental condition would be to label the fake "target" tasks as food-related or not. In the published study, the authors focused on manipulating the situation with the filled and empty bowls, which indicated past participants' behavior and showed that, indeed, such behaviors had an impact on decision making. Moreover, the magazines on healthy versus hedonic eating might be considered as manipulation tactics that influence both the goal state and/or action selection. These magazines should only affect behavior if the decision to take food has already been made. In this task, manipulating the action could pose ethical issues, as this would mean forcing someone to eat. However, this may be accomplished by experiments that relate to the tasting and judging of food, which makes people eat. To manipulate feedback prediction, implementing a prediction error in the feedback loop of the participants would suffice. For example, if the instruction had been that, "eating is voluntary, but know that healthy versus unhealthy food (or vice versa) that does not get eaten will be thrown away," participants might have experienced a conflict between past participants' behavior, the goal prime induced by reading a certain type of magazine, and the type of food that would be thrown away.

To ensure the optimal nudging practice, we suggest that it may be critical to reduce the discrepancy between the optimal outcome (choosing more healthy food) and the initial goal state. Another option for disentangling the influences on goal and direct influences on 
Social influence and feedback control

action, we suggest the use of videos that either depict or do not depict eating behaviors, and that provide a verbal message either promoting or preventing a certain kind of eating behavior (e.g., unhealthy food). While the direct influence on action may be the imitation of the seen, but condemned, behavior, the influence on the goal state should depend on the verbal content of the material. Additionally, all levels of manipulation might try to address either a promotion or a prevention feedback loop.

\section{Boundary Conditions}

To complete the theoretical discourse of the social influence on a target's feedback loop system, we deal with apparent boundary conditions. Our proposed model, and probably influence in general, depends strongly on the reactance of the target. Some people may be more susceptible to influence strategies than others, and these differences may potentially hinder or even exclude the success of social influence. Furthermore, the ability of the target to mentalize the influencer's intentions may interfere with the success of the influencer's exertion of influence. Therefore, highly reactant individuals and people who are good at mentalizing their social interaction partners might not be good targets for applying this framework. However, it may be interesting to examine whether the discrepancy between the reference or goal state and the current state or situation can be relevant to predict reactance. Potentially, a discrepancy that seems too large for the individual may promote reactance.

\section{Conclusions}

We proposed a model of social influence that targets different parts of the internal feedback loop of an interaction partner. To illustrate the need for such a model, we explained how influence on the goal state, action selection, action, and feedback prediction might be in detail. Finally, we analyzed classical experiments on social influence, conformity, and advertisements and applied our model to them. As many of our examples have shown, there are different ways to enter another person's feedback loop through exerting external social 
Social influence and feedback control

influence. However, the stage that gets affected depends strongly on the intentions of the influencer, since the same influence tactic might be interpreted differently within another stage of the feedback loop.

With our proposed model, we wanted to present a new perspective on classic experiments and paradigms that have investigated different kinds of social influence, and we also tried to classify them according to our model. Future studies should aim to selectively examine the single stages of social influence and to combine this model with other models, such as reinforcement learning. In our view, understanding how to influence only one particular aspect and exclude the influence at another aspect may be crucial for a more detailed perspective on social influence. 


\section{References}

Aaker, J. L., \& Lee, A. Y. (2001). "I" seek pleasures and “we" avoid pains: The role of selfregulatory goals in information processing and persuasion. Journal of Consumer Research, 28(1), 33-49. https://doi.org/10.1086/321946

Aquino, K. (1998). The effects of ethical climate and the availability of alternatives on the use of deception during negotiation. International Journal of Conflict Management, 9(3), 195-217. https://doi.org/10.1108/eb022809

Asch, S. E. (1940). Studies in the principles of judgments and attitudes: II. Determination of judgments by group and by ego standards. Journal of Social Psychology, 12(2), 433465. https://doi.org/10.1080/00224545.1940.9921487

Bednark, J. G., \& Franz, E. A. (2014). Agency attribution: event-related potentials and outcome monitoring. Experimental Brain Research, 232(4), 1117-1126. https://doi.org/10.1007/s00221-014-3821-4

Behne, N., Scheich, H., \& Brechmann, A. (2008). The left dorsal striatum is involved in the processing of neutral feedback. NeuroReport, 19(15), 1497-1500. https://doi.org/10.1097/WNR.0b013e32830fe98c

Brown, V. J., \& Bowman, E. M. (1995). Discriminative cues indicating reward magnitude continue to determine reaction time of rats following lesions of the nucleus accumbens. European Journal of Neuroscience, 7(12), 2479-2485. https://doi.org/10.1111/j.14609568.1995.tb01046.x

Buss, D. M. (1992). Manipulation in close relationships: five personality factors in interactional context. Journal of Personality, 60(2), 477-499. https://doi.org/10.1111/j.1467-6494.1992.tb00981.x

Carver, C. S. (2004). Self-regulation of action and affect. In K. D. Vohs \& R. F. Baumeister (Eds.), Handbook of self-regulation: Research, theory, and applications. (pp. 13-39). The Guilford Press. 
Social influence and feedback control

Carver, C. S., \& Scheier, M. F. (1981). Attention and self-regulation: A control-theory approach to human behavior. Springer-Verlag New York. https://doi.org/10.1007/978$1-4612-5887-2$

Carver, C. S., \& Scheier, M. F. (2000a). Scaling back goals and recalibration of the affect system are processes in normal adaptive self-regulation: Understanding "response shift" phenomena. Social Science and Medicine, 50(12), 1715-1722. https://doi.org/10.1016/S0277-9536(99)00412-8

Carver, C. S., \& Scheier, M. F. (2000b). On the structure of behavioral self-regulation. In M. Boekaerts, P. R. Pintrich, \& M. Zeidner (Eds.), Handbook of self-regulation (pp. 41-84). Academic Press. https://doi.org/10.1016/b978-012109890-2/50032-9

Cesario, J., \& Higgins, E. T. (2008). Making message recipients "feel right": How nonverbal cues can increase persuasion. Psychological Science, 19(5), 415-420. https://doi.org/10.1111/j.1467-9280.2008.02102.x

Chambon, V., \& Haggard, P. (2012). Sense of control depends on fluency of action selection, not motor performance. Cognition, 125(3), 441-451. https://doi.org/10.1016/j.cognition.2012.07.011

Chang, C. C., \& Chou, Y. J. (2008). Goal orientation and comparative valence in persuasion. Journal of Advertising, 37(1), 73-87. https://doi.org/10.2753/JOA0091-3367370106

Cialdini, R. B., Reno, R. R., \& Kallgren, C. A. (1990). A focus theory of normative conduct: recycling the concept of norms to reduce littering in public places. Journal of Personality and Social Psychology, 58(6), 1015-1026. https://doi.org/10.1037/00223514.58.6.1015

Cullum, J., Armeli, S., \& Tennen, H. (2010). Drinking norm-behavior association over time using retrospective and daily measures. Journal of Studies on Alcohol and Drugs, 71(5), 769-777. https://doi.org/10.15288/jsad.2010.71.769 
Social influence and feedback control

DeBono, K. G., \& Packer, M. (1991). The effects of advertising appeal on perceptions of product quality. Personality and Social Psychology Bulletin, 17(2), 194-200. https://doi.org/10.1177/014616729101700212

Deutsch, M., \& Gerard, H. B. (1955). A study of normative and informational social influences upon individual judgment. Journal of Abnormal and Social Psychology, 51(3), 629-636. https://doi.org/10.1037/h0046408

Dillard, J., \& Pfau, M. (2002). The persuasion handbook: Developments in theory and practice. SAGE Publications. https://doi.org/10.4135/9781412976046

Druckman, J. N. (2001). Using credible advice to overcome framing effects. Journal of Law, Economics, and Organization, 17(1), 62-82. https://doi.org/10.1093/jleo/17.1.62

Eitam, B., \& Higgins, E. T. (2010). Motivation in mental accessibility: Relevance of a Representation (ROAR) as a new framework. Social and Personality Psychology Compass, 4(10), 951-967. https://doi.org/10.1111/j.1751-9004.2010.00309.x

Elsner, B., \& Hommel, B. (2001). Effect anticipation and action control. Journal of Experimental Psychology: Human Perception and Performance, 27(1), 229-240. https://doi.org/10.1037/0096-1523.27.1.229

Falk, E., \& Scholz, C. (2018). Persuasion, influence, and value: Perspectives from communication and social neuroscience. Annual Review of Psychology, 69, 329-356. https://doi.org/10.1146/annurev-psych-122216-011821

Fischer, A. H., Manstead, A. S. R., \& Zaalberg, R. (2003). Social influences on the emotion process. European Review of Social Psychology, 14(1), 171-201. https://doi.org/10.1080/10463280340000054

Fiske, S. T. (1993). Controlling other people: the impact of power on stereotyping. American Psychologist, 48(6), 621-628. https://doi.org/10.1037/0003-066X.48.6.621

Freedman, J. L., \& Fraser, S. C. (1966). Compliance without pressure: the foot-in-the-door 
Social influence and feedback control

technique. Journal of Personality and Social Psychology, 4(2), 195-202. https://doi.org/10.1037/h0023552

French, J. R. P., \& Raven, B. (1959). The bases of social power. In D. Cartwright (Ed.), Studies in social power (pp. 150-167). University of Michigan.

Frick, T. W., Li, T., \& Pavlou, P. (2018). Social influence and visual attention in the personalization privacy paradox for social advertising: an eye tracking study. WISP 2018 Proceedings, 8 .

Gächter, S., Orzen, H., Renner, E., \& Starmer, C. (2009). Are experimental economists prone to framing effects? A natural field experiment. Journal of Economic Behavior and Organization, 70(3), 443-446. https://doi.org/10.1016/j.jebo.2007.11.003

Goldstein, N. J., Cialdini, R. B., \& Griskevicius, V. (2008). A room with a viewpoint: Using social norms to motivate environmental conservation in hotels. Journal of Consumer Research, 35(3), 472-482. https://doi.org/10.1086/586910

Haddock, G., Maio, G. R., Arnold, K., \& Huskinson, T. (2008). Should persuasion be affective or cognitive? The moderating effects of need for affect and need for cognition. Personality and Social Psychology Bulletin, 34(6), 769-778. https://doi.org/10.1177/0146167208314871

Harkins, S. G., Williams, K. D., \& Burger, J. M. (2017). The Oxford handbook of social influence. Oxford University Press. https://doi.org/10.1093/oxfordhb/9780199859870.001.0001

Higgins, E. T. (1997). Beyond pleasure and pain. American Psychologist, 52(12), 1280-1300. https://doi.org/10.1037/0003-066x.52.12.1280

Higgins, E. T. (1998). Promotion and Prevention: regulatory Focus as A Motivational Principle. Advances in Experimental Social Psychology, 30, 1-46. https://doi.org/10.1016/S0065-2601(08)60381-0 
Social influence and feedback control

Higgins, E. T. (1999). Promotion and prevention as a motivational duality: implications for evaluative processes. In S. Chaiken \& Y. Trope (Eds.), Dual-process theories in social psychology (pp. 503-525). The Guilford Press.

Higgins, E. T., \& Eitam, B. (2014). Priming-shmiming: it's about knowing when and why stimulated memory representations become active. Social Cognition, 32, 225-242. https://doi.org/10.1521/soco.2014.32.supp.225

Holler, M., Hoelzl, E., Kirchler, E., Leder, S., \& Mannetti, L. (2008). Framing of information on the use of public finances, regulatory fit of recipients and tax compliance. Journal of Economic Psychology, 29(4), 597-611. https://doi.org/10.1016/j.joep.2008.01.001

Hommel, B., \& Elsner, B. (2009). Acquisition, representation, and control of action. In E. Morsella, J. A. Bargh, \& P. M. Gollwitzer (Eds.), Social cognition and social neuroscience. Oxford handbook of human action (pp. 371-398). Oxford University Press.

Jäger, A., Loschelder, D. D., \& Friese, M. (2015). How self-regulation helps to master negotiation challenges: An overview, integration, and outlook. European Review of Social Psychology, 26(1), 203-246. https://doi.org/10.1080/10463283.2015.1112640

Keltner, D., Gruenfeld, D. H., \& Anderson, C. (2003). Power, approach, and inhibition. Psychological Review, 110(2), 265-284. https://doi.org/10.1037/0033-295X.110.2.265

Lavine, H., \& Snyder, M. (1996). Cognitive processing and the functional matching effect in persuasion: The mediating role of subjective perceptions of message quality. Journal of Experimental Social Psychology, 32(6), 580-604.

https://doi.org/10.1006/jesp.1996.0026

Lee, A. Y., \& Aaker, J. L. (2004). Bringing the frame into focus: the influence of regulatory fit on processing fluency and persuasion. Journal of Personality and Social Psychology, 86(2), 205-218. https://doi.org/10.1037/0022-3514.86.2.205 
Social influence and feedback control

Leotti, L. A., \& Delgado, M. R. (2011). The inherent reward of choice. Psychological Science, 22(10), 1310-1318. https://doi.org/10.1177/0956797611417005

Levi, D., \& Askay, D. A. (2015). Group dynamics for teams. SAGE Publications.

Lewin, K. (1941). Analysis of the concepts whole, differentiation, and unity. University of Iowa Studies in Child Welfare, 18(1), 226-261.

Loersch, C., \& Payne, B. K. (2011). The persuasive effects of verbal and nonverbal information in a context of value relevance. Perspectives on Psychological Science, 6(3), 234-252. https://doi.org/10.1177/1745691611406921

Marsh, K. L., Hart-O’Rourke, D. M., \& Julka, D. L. (1997). The Persuasive Effects of Verbal and Nonverbal Information in a Context of Value Relevance. Personality and Social Psychology Bulletin, 23(6), 563-579. https://doi.org/10.1177/0146167297236001

McClelland, K. A., \& Fararo, T. J. (2006). Purpose, meaning, and action: control systems theories in sociology. Palgrave-MacMillan.

Milgram, S. (1963). Behavioral study of obedience. Journal of Abnormal and Social Psychology, 67(4), 371-378. https://doi.org/10.1037/h0040525

Min, K. S., Martin, D., \& Jung, J. M. (2013). Designing advertising campaigns for destinations with mixed images: using visitor campaign goal messages to motivate visitors. Journal of Business Research, 66(6), 759-764.

https://doi.org/10.1016/j.jbusres.2011.09.015

Nelson, T. E., \& Kinder, D. R. (1996). Issue frames and group-centrism in American public opinion. Journal of Politics, 58(4), 1055-1078. https://doi.org/10.2307/2960149

Nelson, T. E., Oxley, Z. M., \& Clawson, R. A. (1997). Toward a psychology of framing effects. Political Behavior, 19(3), 221-246. https://doi.org/10.1023/A:1024834831093

Petty, R. E., Brinol, P., Loersch, C., \& McCaslin, M. J. (2009). The need for cognition. In R. Leary \& R. H. Hoyle (Eds.), Handbook of individual differences in social behavior (pp. 
Social influence and feedback control

318-329). The Guilford Press.

Petty, R. E., \& Cacioppo, J. T. (1979). Issue involvement can increase or decrease persuasion by enhancing message-relevant cognitive responses. Journal of Personality and Social Psychology, 37(10), 1915-1926. https://doi.org/10.1037/0022-3514.37.10.1915

Petty, R. E., \& Cacioppo, J. T. (1986). Communication and persuasion: central and peripheral routes to attitude change. Springer. https://doi.org/10.1007/978-1-46124964-1

Petty, R. E., \& Wegener, D. T. (1998). Matching Versus Mismatching Attitude Functions: Implications for Scrutiny of Persuasive Messages. Personality and Social Psychology Bulletin, 24(3), 227-240. https://doi.org/10.1177/0146167298243001

Poels, K., \& Dewitte, S. (2008). Hope and self-regulatory goals applied to an advertising context. Promoting prevention stimulates goal-directed behavior. Journal of Business Research, 61(10), 1030-1040. https://doi.org/10.1016/j.jbusres.2007.09.019

Price, V., \& Tewksbury, D. (1997). News values and public opinion: a theoretical account of media priming and framing. In G. A. Barett \& F. J. Boster (Eds.), Progress in the communication sciences (Vol. 13, pp. 173-212). Ablex.

Prinsen, S., de Ridder, D. T. D., \& de Vet, E. (2013). Eating by example. Effects of environmental cues on dietary decisions. Appetite, 70, 1-5. https://doi.org/https://doi.org/10.1016/j.appet.2013.05.023

Raven, B. H. (1992). A power/interaction model of interpersonal influence: French and Raven thirty years later. Journal of Social Behavior \& Personality, 7(2), 217-244.

Redgrave, P., \& Gurney, K. (2006). The short-latency dopamine signal: a role in discovering novel actions? Nature Reviews Neuroscience, 7(12), 967-975.

https://doi.org/10.1038/nrn2022

Redgrave, P., Gurney, K., \& Reynolds, J. (2008). What is reinforced by phasic dopamine 
Social influence and feedback control

signals? In Brain Research Reviews (Vol. 58, Issue 2, pp. 322-339). Elsevier. https://doi.org/10.1016/j.brainresrev.2007.10.007

Redgrave, P., Prescott, T. J., \& Gurney, K. (1999). The basal ganglia: A vertebrate solution to the selection problem? Neuroscience, 89(4), 1009-1023. https://doi.org/10.1016/S03064522(98)00319-4

Robinson, D. T. (2007). Control theories in sociology. Annual Review of Sociology, 33, 157174. https://doi.org/10.1146/annurev.soc.32.061604.123110

Samejima, K., Ueda, Y., Doya, K., \& Kimura, M. (2005). Representation of action-specific reward values in the striatum. Science, 310(5752), 1337-1340. https://doi.org/10.1126/science.1115270

Schneider, D., Lins, S., Grupp, T., Benlian, A., \& Sunyaev, A. (2017). Nudging users into online verification: the case of carsharing platforms. ICIS 2017: Transforming Society with Digital Innovation.

Schultz, W. P., Khazian, A. M., \& Zaleski, A. C. (2008). Using normative social influence to promote conservation among hotel guests. Social Influence, 3(1), 4-23. https://doi.org/10.1080/15534510701755614

Sherif, M. (1936). The psychology of social norms. Harper \& Brothers.

Sip, K. E., Skewes, J. C., Marchant, J. L., McGregor, W. B., Roepstorff, A., \& Frith, C. D. (2012). What if I Get Busted? Deception, Choice, and Decision-Making in Social Interaction. Frontiers in Neuroscience, 6, 58. https://doi.org/10.3389/fnins.2012.00058

Slater, M., Antley, A., Davison, A., Swapp, D., Guger, C., Barker, C., Pistrang, N., \& Sanchez-Vives, M. V. (2006). A virtual reprise of the Stanley Milgram obedience experiments. PLoS ONE, I(1), e39. https://doi.org/10.1371/journal.pone.0000039

Spiegel, S., Grant-Pillow, H., \& Tory Higgins, E. (2004). How regulatory fit enhances motivational strength during goal pursuit. European Journal of Social Psychology, 
Social influence and feedback control

34(1), 39-54. https://doi.org/10.1002/ejsp.180

Stayton, D. J., Hogan, R., \& Ainsworth, M. D. (1971). Infant obedience and maternal behavior: the origins of socialization reconsidered. Child Development, 42(4), 1057. https://doi.org/10.2307/1127792

Thaler, R. H., \& Sunstein, C. R. (2008). Nudge: improving decisions about health, wealth, and happiness. Yale University Press.

Thibaut, J. W., \& Kelley, H. H. (1959). The social psychology of groups. John Wiley \& Sons, Inc.

Tricomi, E. M., Delgado, M. R., \& Fiez, J. A. (2004). Modulation of caudate activity by action contingency. Neuron, 41(2), 281-292. https://doi.org/10.1016/S08966273(03)00848-1

Tversky, A., \& Kahneman, D. (1981). The framing of decisions and the psychology of choice. Science, 211(4481), 453-458. https://doi.org/10.1126/science.7455683

vanDellen, M. R., \& Hoyle, R. H. (2010). Regulatory accessibility and social influences on state self-control. Personality and Social Psychology Bulletin, 36(2), 251-263.

https://doi.org/10.1177/0146167209356302

Vansteenkiste, M., Simons, J., Lens, W., Sheldon, K. M., \& Deci, E. L. (2004). Motivating learning, performance, and persistence: the synergistic effects of intrinsic goal contents and autonomy-supportive contexts. Journal of Personality and Social Psychology, 87(2), 246-260. https://doi.org/10.1037/0022-3514.87.2.246

Vescio, T. K., Butz, D. A., \& Snyder, M. (2003). Power in stereotypically masculine domains: a Social Influence Strategy $\times$ Stereotype Match Model. Journal of Personality and Social Psychology, 85(6), 1062-1078. https://doi.org/10.1037/0022-3514.85.6.1062 von Bertalanffy, L. (1950). An outline of general system theory. British Journal for the Philosophy of Science, 1(2), 134-165. https://doi.org/10.1093/bjps/I.2.134 
Social influence and feedback control

von Hippel, W., \& Trivers, R. (2011). Reflections on self-deception. Behavioral and Brain Sciences, 34(1), 41-56. https://doi.org/10.1017/S0140525X10003018

Wheeler, L. (1966). Motivation as a determinant of upward comparison. Journal of Experimental Social Psychology, 1(Suppl. 1), 27-31. https://doi.org/10.1016/00221031(66)90062-X

Wiener, N. (1949). Cybernetics: control and communication in the animal and the machine. The Economic Journal, 59(236), 573-575. https://doi.org/10.2307/2226579

Willer, R., Kuwabara, K., \& Macy, M. W. (2009). The false enforcement of unpopular norms. American Journal of Sociology, 115(2), 451-490. https://doi.org/10.1086/599250

Wills, T. A. (1981). Downward comparison principles in social psychology. Psychological Bulletin, 90(2), 245-271. https://doi.org/10.1037/0033-2909.90.2.245

Wolpert, D. M., Doya, K., \& Kawato, M. (2003). A unifying computational framework for motor control and social interaction. Philosophical Transactions of the Royal Society B: Biological Sciences, 358(1431), 593-602. https://doi.org/10.1098/rstb.2002.1238

Yukl, G. (1989). Managerial leadership: a review of theory and research. Journal of Management, 15(2), 251-289. https://doi.org/10.1177/014920638901500207

Zhao, G., \& Pechmann, C. (2007). The impact of regulatory focus on adolescents' response to antismoking advertising campaigns. Journal of Marketing Research, 44(4), 671-687. https://doi.org/10.1509/jmkr.44.4.671 